\section{Pauliceia 2.0: mapeamento colaborativo da história de São Paulo, 1870-1940}

\section{Pauliceia 2.0: collaborative mapping of the history of São Paulo, 1870-1940}

\section{Luis Ferla ${ }^{i}$ \\ orcid.org/0000-0003-3617-2560 \\ ferla@unifesp.br}

Karine Reis Ferreira ${ }^{i i}$

orcid.org/0000-0003-2656-5504

Fernando Atique ${ }^{i}$

orcid.org/0000-0002-7681-1227

\section{Andrew G. Brittiii}

orcid.org/0000-0001-9938-3010

\section{Karla Donato Fook ${ }^{\text {iv }}$} orcid.org/0000-0002-3631-2554

\begin{abstract}
Jeffrey Lesser ${ }^{v}$ orcid.org/0000-0001-6386-7187
\end{abstract} Cristiane Miyasaka ${ }^{v i}$ orcid.org/0000-0002-5222-7528

\section{Daniela Musa ${ }^{i}$} orcid.org/0000-0002-8405-959X

Thomas D. Rogers ${ }^{\text {vii }}$ orcid.org/0000-0002-1077-6182

\section{Nandamudi \\ Vijaykumari, ii}

orcid.org/0000-0002-9025-0841
' Universidade Federal de São Paulo. Guarulhos - SP - Brasil. ii Instituto Nacional de Pesquisas Espaciais. São José dos Campos - SP - Brasil. iii University of North Carolina School of the Arts. Winston-Salem - NC - EUA. iv Instituto Tecnológico de Aeronáutica. São José dos Campos - SP - Brasil. ${ }^{v}$ Halle Institute for Global Research/Emory University. Atlanta - GA - EUA.

vi Prefeitura Municipal de Campinas. Campinas - SP - Brasil. vii Emory University. Atlanta - GA - EUA.

Recebido em 7 nov. 2019.

Aprovado em 5 dez. 2019.
FERLA, Luis et al. Pauliceia 2.0: mapeamento colaborativo da história de São Paulo (1870-1940). História, Ciências, Saúde - Manguinhos, Rio de Janeiro, v.27, n.4, out.-dez. 2020, p.1207-1223.

Resumo

$\mathrm{O}$ artigo apresenta novas abordagens para investigar o passado usando tecnologias digitais. O projeto "Pauliceia 2.0: mapeamento colaborativo da história de São Paulo (1870-1920)" é de código aberto e visa engajar o público de maneira ampla, usando metodologias colaborativas. O texto discute a concepção do projeto, seu estágio atual e suas perspectivas. Além disso, também se oferece o Pauliceia 2.0 como um estudo de caso para discutir a relação entre tecnologias digitais e métodos históricos. O resultado desse percurso, ao menos essa é a intenção dos autores listados e dos demais integrantes da equipe do projeto, nomeados ao final do artigo, almeja ressignificar o trabalho em questão na confluência entre humanidades digitais, história pública e ciência aberta.

Palavras-chave: ciência aberta; humanidades digitais; história pública; história digital; história de São Paulo.

\section{Abstract}

This article presents new approaches for investigating the past using digital technologies. "Pauliceia 2.0: collaborative mapping of the history of São Paulo (18701920)" is an open-source project intended to broadly engage with the public through collaborative methodologies. This text discusses the concept, current status, and prospects of this project, and presents it as a case study to discuss the relationship between digital technologies and historical methods. The product of this journey (at least the outcome intended by the authors and the other team members listed at the end of the article) is meant to assign new meaning to the project at the juncture between digital humanities, public history, and open science.

Keywords: open science; digital humanities; public history; digital history; history of São Paulo. 
$\mathrm{O}$ presente texto tem o objetivo de apresentar o projeto "Pauliceia 2.0: mapeamento colaborativo da história de São Paulo (1870-1940)", discutindo sua concepção, seu estágio atual e suas perspectivas. Em se tratando de uma iniciativa aberta e colaborativa, o interesse em publicar um artigo que trate do projeto vai além de uma estratégia de divulgação de pesquisas e resultados, o que em si já se justifica como parte de um ethos valorizado e saudável do mundo acadêmico e científico. Iniciativas colaborativas podem fracassar por diversas razões, e uma das mais frequentes é bastante trivial: a falta de conhecimento da existência do projeto por parte daqueles que constituiriam o seu público-alvo prioritário. Um segundo objetivo do texto é oferecer o projeto em questão como estudo de caso que permita discutir as relações entre as tecnologias digitais e o trabalho do historiador. Para fazer isso, quatro "paradas" serão executadas ao longo do texto, fazendo a transição da discussão específica do projeto para reflexões que abordem os aspectos mais gerais das ressignificações tecnológicas da produção do conhecimento em história e ciências humanas. O resultado desse percurso, ao menos essa é a intenção dos autores, é a reapresentação do projeto na confluência entre humanidades digitais, história pública e ciência aberta.

\section{O projeto}

O objetivo do projeto é disponibilizar, na rede mundial de computadores, uma plataforma aberta que permita, como seu título indica, o mapeamento colaborativo da história da cidade de São Paulo durante o período de sua modernização urbano-industrial, de 1870 a $1940 .{ }^{1}$ Por meio de uma interface aberta e amigável, qualquer pesquisador interessado poderá alimentar os seus dados espacializáveis à plataforma (uma versão beta da plataforma se encontra disponível no endereço <www.pauliceia.dpi.inpe.br>; ver Figuras 1 e 2). Por um lado, o pesquisador em questão terá, de imediato, uma visualização de sua própria pesquisa, permitindo o seu uso em produções científicas, como monografias, artigos, teses etc. Por outro, a cada alimentação realizada, a base comum será enriquecida, transformando-se ela mesma em acervo de material de pesquisa passível de dar suporte a reflexões e debates historiográficos.

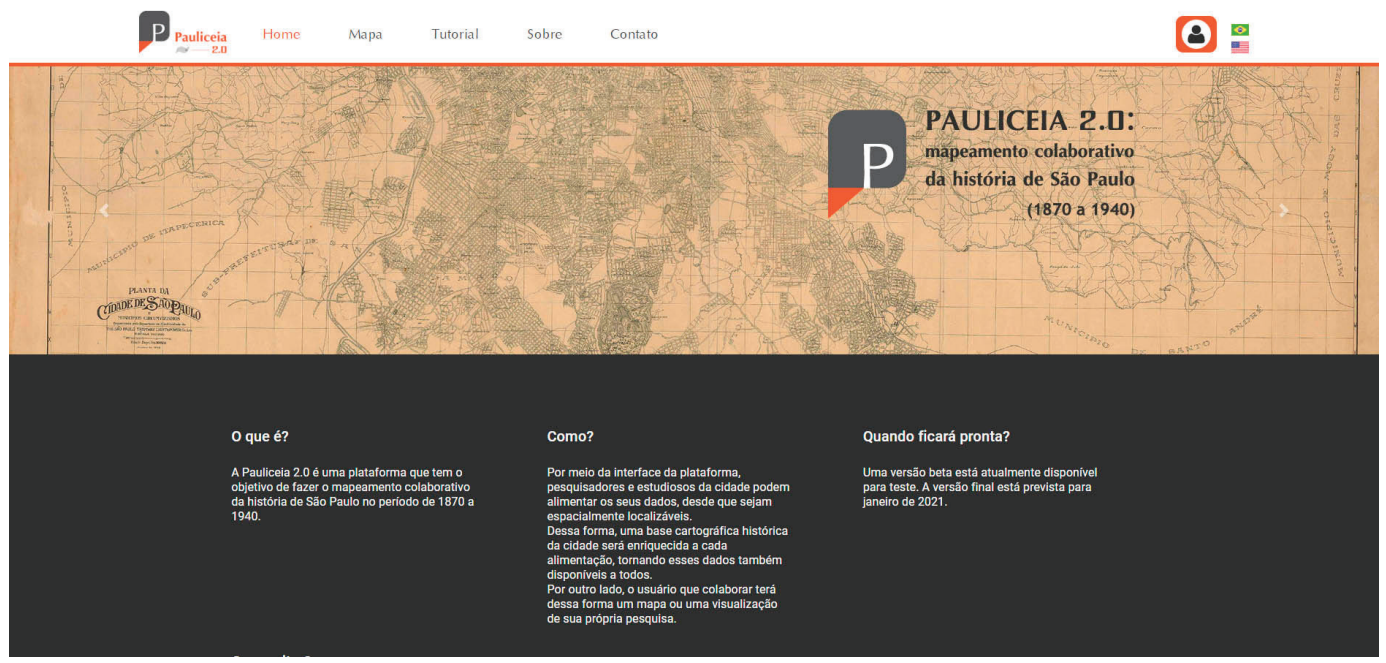

Figura 1: Homepage da plataforma em sua versão beta (<www.pauliceia.dpi.inpe.br>) 


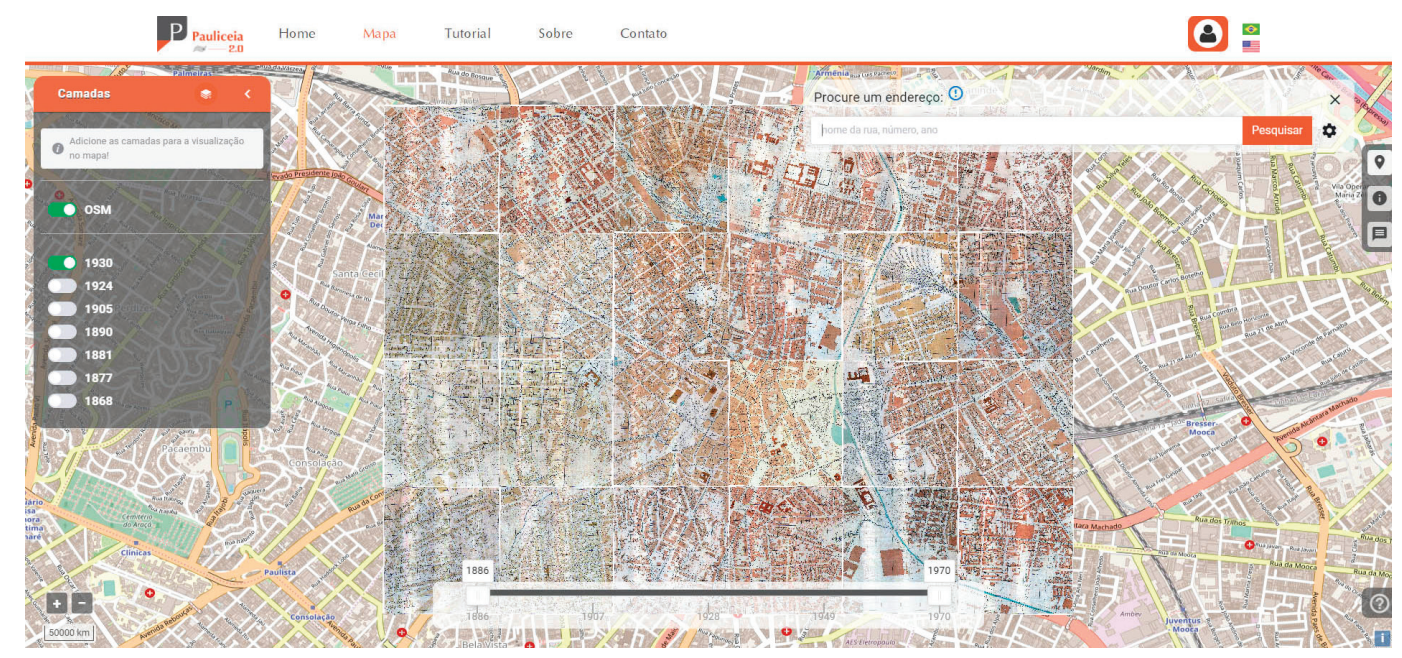

Figura 2: Aba dos mapas e do geolocalizador em versão beta (<www.pauliceia.dpi.inpe.br $>$ )

O recorte espaçotemporal da plataforma, a São Paulo de 1870 a 1940, foi escolhido por corresponder a um período de transformações particularmente radicais, de profundidade e intensidade quase únicas na história. De 1870 a 1940, a população da cidade passou de 31.385 a 1.326.261 habitantes (IBGE, 2011). Evidentemente, o processo explosivo de urbanização não era idiossincrasia de São Paulo no período. Muitas cidades o protagonizaram em nível global, como Rio de Janeiro, Buenos Aires, Nova York ou Chicago. Mas poucas partiram de patamares populacionais tão baixos como os de São Paulo, para chegar próximo ao primeiro milhão poucas décadas depois. Por outro lado, não é apenas o aspecto quantitativo dessas transformações que interessa, mas também os qualitativos. A cidade que emergia daquele período era uma metrópole industrial e se distanciava do "burgo de estudantes" de meados do século anterior (Bruno, 1954) na mesma medida em que a modernidade se afastava da pré-modernidade. Justamente por isso, o recorte proposto possui uma considerável densidade de produção historiográfica, o que lhe confere uma justificativa adicional para a sua escolha, agora de caráter tático. Quanto maior e mais produtiva a comunidade atinente a um projeto colaborativo, maiores as suas chances de prosperar.

\section{Um Google Maps do passado?}

Ao propor a espacialização de dados de pesquisas envolvendo o recorte indicado, um primeiro desafio, ao mesmo tempo de caráter historiográfico e computacional, impõe-se: a geolocalização, ou seja, a transformação de um texto que informa um determinado endereço em coordenadas geográficas no mundo real. Todos aqueles que se propuseram a produzir visualizações cartográficas a partir de endereços do passado já se depararam com esse problema: o desenho do sistema viário, sua toponímia e, principalmente, a numeração dos imóveis sofreram alterações significativas durante e desde o período estudado, o que inviabiliza o uso de geolocalizadores do mundo atual, como Google Maps, Open Street Map e similares. Ainda que a criação de camadas na plataforma não se restrinja apenas 
a dados espacializados a partir de endereços, ${ }^{2}$ a equipe do projeto admitiu a hipótese de que esse seria o caso de parte importante dos potenciais usuários, quando não da maioria deles. Assim, não havia alternativa a não ser desenvolver um "geolocalizador do passado", adaptado à cidade de São Paulo do período.

Para fazer isso, foi estruturado um banco de dados com endereços conhecidos, a partir do qual a ferramenta faria a geolocalização, ou utilizando diretamente o ponto alimentado ao banco, ou fazendo extrapolações a partir do que ali constasse. Por "endereço conhecido" entenda-se um ponto do qual se conhecem quatro atributos: nome da rua, número do imóvel, ano ou período em que tal endereço foi válido e suas coordenadas no espaço. À equipe de historiadores do projeto cabia então o levantamento e a organização da documentação que permitisse a alimentação do banco. A equipe computacional, por sua vez, dedicar-se-ia ao desenvolvimento do algoritmo que fizesse a ferramenta funcionar adequadamente. ${ }^{3}$ Dadas a envergadura e a complexidade da construção do banco de dados em questão, destinado a cobrir todas as ruas da cidade no período do recorte, optou-se por definir uma área-piloto para ser priorizada na primeira etapa do projeto. Tal área corresponde aproximadamente ao centro da cidade, definido a partir do sistema viário indicado pela carta de 1868 (São Paulo, 1954). Apenas essa área possui cerca de quinhentos logradouros, o que perfaz aproximadamente três mil pontos alimentados, já que de cada rua foram coletados três imóveis com números ímpares e três com números pares.

A documentação histórica privilegiada para a construção do banco foi o "livro de emplacamento", registro mantido pela municipalidade para justamente anotar, relativa a cada rua da cidade, a mudança da numeração dos imóveis sempre que um novo emplacamento fosse realizado. Dessa forma, com a ajuda dessa fonte, poder-se-ia coletar um conjunto de imóveis por rua dos quais seria possível saber o período em que tiveram validade. Mas persistia ainda a dificuldade em localizar esses pontos no espaço. Uma lei sobre o tema, de finais de 1929, destinada a racionalizar o sistema de numeração, implantando na cidade o chamado "sistema americano", seria a chave para a resolução do problema (Prefeitura..., 19 nov. 1929). Como ela determinava que o número do imóvel fosse estabelecido pela distância em metros até o começo da rua (com os arredondamentos necessários), os emplacamentos a ela posteriores já passaram a incorporar, conceitual e explicitamente, a informação da localização. Como cada emplacamento indicava também o número anterior, que fora substituído, e como há um livro-índice que informa todas as datas em que cada rua recebeu um novo emplacamento, foi possível fazer retroceder a história da numeração de imóveis selecionados até o primeiro emplacamento registrado (os livros de emplacamento começaram a ser utilizados na primeira década do século XX).

Para compreender o funcionamento prático do geolocalizador, imagine-se um usuário que pretenda determinar onde estaria um imóvel de número 50, de determinada rua, em 1937. Na parte A da Figura 3 estão indicados os pontos alimentados ao banco de dados (em azul) da rua hipotética, com suas respectivas numerações e períodos de vigência. $\mathrm{Na}$ parte $\mathrm{B}$, em amarelo, aparecem os pontos utilizados para a geolocalização solicitada (os demais se referem a períodos que caem fora da data indicada pelo usuário). O ponto em vermelho que aparece na parte $C$ é a localização determinada pelo algoritmo, obtida pela extrapolação métrica entre os imóveis de número 14 e $60 .{ }^{4}$ 


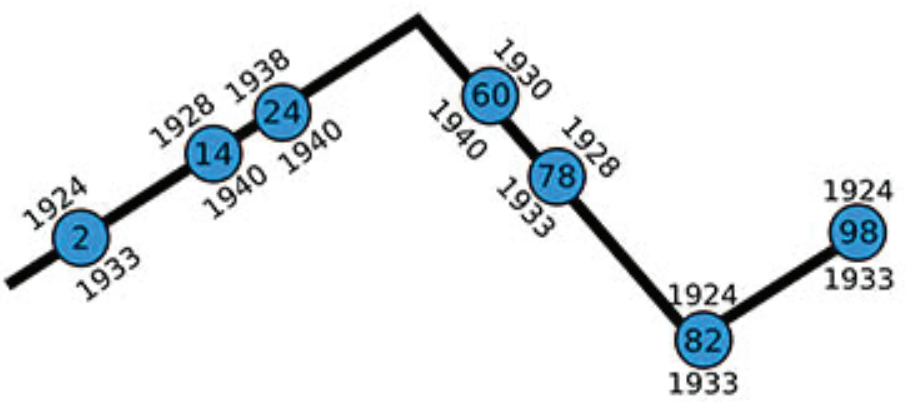

A

- Street

1924 Start Date

(98) Number

1933 Final Date

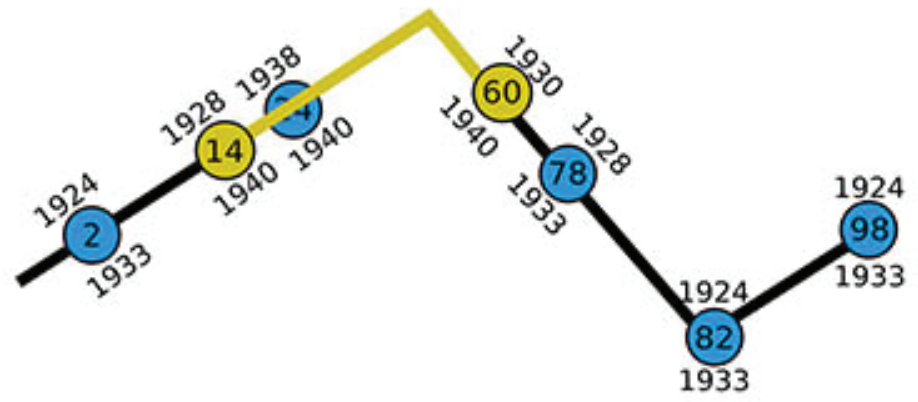

B

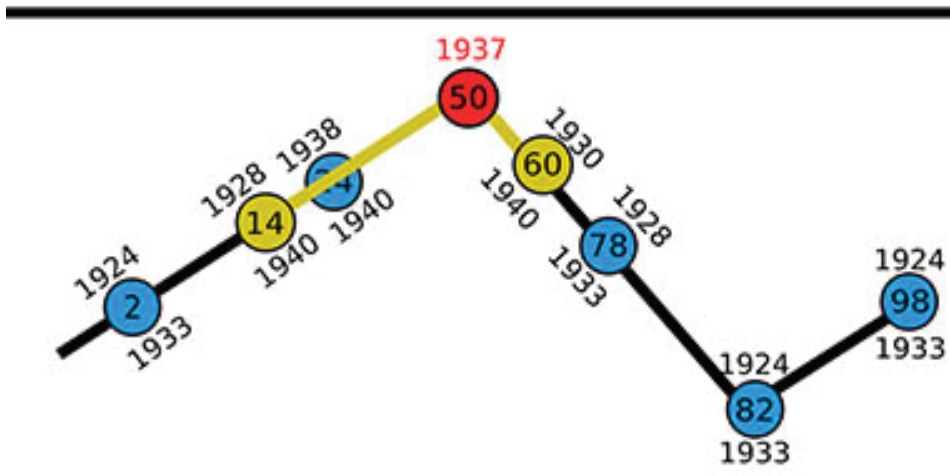

Figura 3: Exemplo de geolocalização a partir do banco de dados do projeto (Ferreira et al., 2018, p.300)

O banco de dados do geolocalizador segue em construção, os limites de sua abrangência se afastando da área-piloto inicial e buscando se aproximar cada vez mais da mancha urbana total da cidade no período. A ferramenta já se encontra operacional e disponível no portal da plataforma. O geolocalizador do projeto Pauliceia representa, assim, um primeiro exemplo de articulação entre saberes historiográficos e computacionais que implicou acomodações e negociações importantes entre as exigências de precisão das máquinas e o mundo ambíguo e matizado do passado. 


\section{Primeira parada: as tensas relações entre história e tecnologia}

A partir do reconhecimento da onipresença das tecnologias digitais e de sua enorme capilaridade social no mundo de hoje, torna-se inevitável confrontar o tema da sua influência no trabalho dos pesquisadores em humanidades, em geral, e dos historiadores, em particular. Se, por um lado, o uso dessas tecnologias nessas áreas se difunde cada vez mais, e com elas novas e promissoras possibilidades de investigação e de circulação dos seus resultados se afirmam, por outro lado, desafios consideráveis se impõem, no mais das vezes relacionados a sérias e persistentes incompatibilidades entre o mundo dos computadores e suas exigências maquínicas e o mundo das humanidades, sempre à volta com as subjetividades e as ambiguidades inerentes à fabricação e à interpretação da vida social. Se assim é para as ciências humanas em geral, mais crítica é a situação dos historiadores, no que a isso se refere. Não apenas o objeto da história apresenta nuanças, ambiguidades e incompletudes (Bodenhamer, 2008, p.222), como ele é inerentemente fugidio, com seu centro de gravidade não mais no presente, mas no passado.

Essas tensões intrínsecas entre tecnologia e história ajudam a entender as resistências de muitos pesquisadores ao uso da computação em seu trabalho. Os riscos de uma mistificação quantitativista do conhecimento histórico, com tonalidades fortemente positivistas, sempre acompanharam a relação dos pesquisadores do passado com as diversas tecnologias digitais (Gregory, Ell, 2007, p.13-14; White, 2008, p.IX; Churchill, Hillier, 2008, p.62). Assim foi com a onda da história demográfica e econômica dos anos 1960 e 1970, produzida por centros de pesquisa qualificados e bem aparelhados com maquinaria de alto custo, fora do alcance da maioria dos pesquisadores mundo afora. E, em certa medida, ainda o é, mesmo após as sucessivas revoluções tecnológicas desde então, que facilitaram enormemente o acesso às estruturas e infraestruturas computacionais.

Hoje, o historiador enfrenta o desafio de escolher ou persistir na negação obstinada da utilização das tecnologias digitais em seu trabalho ou explorar as possibilidades oferecidas por elas e buscar "estratégias de adaptação" que tratem das contradições referidas acima. A segunda opção parece, a um só tempo, a mais promissora e a mais realista, tanto pela pressão da facilitação generalizada do acesso às tecnologias como por questões geracionais que as tornam cada vez mais familiares aos pesquisadores mais jovens.

Mas quais seriam essas "estratégias de adaptação" referidas? Primeiramente, a valorização dos metadados, ou seja, dos dados sobre os dados (Gregory, Ell, 2007, p.5761). Todo conhecimento que é apresentado como resultado, ainda que parcial, de algum processamento computacional, carrega consigo, como que de contrabando, uma autoridade amplificada e ilegítima. Os autores da pesquisa devem deixar o mais claro possível todas as aproximações e hipóteses assumidas na produção dos resultados. Isso, em si, não é novidade para os que exercem a boa prática científica, seja em que área for. Mas se é assim em geral, para o historiador digital essa preocupação ganha prioridade adicional, pois o risco de percepções equivocadas acerca dos resultados e significados da pesquisa é relativamente maior.

No que se refere às geotecnologias, mais afeitas ao projeto que ora é apresentado, o desenvolvimento de simbologias da imprecisão é outra estratégia que pode ser útil aos 
historiadores (Knowles, 2008, p.19). Por exemplo, a área de abrangência de determinado fenômeno não precisa ser delimitada por um polígono bem definido, mas por uma mancha ou um borrão, que pode dar uma ideia melhor da imprecisão de sua localização. ${ }^{5}$ Outra estratégia comum é apresentar as visualizações espaciais utilizando como mapa de fundo as imagens fotográficas de mapas históricos originais (raster), pois as cicatrizes do tempo, como rasgos e deformações, reforçam as percepções de imprecisão junto aos possíveis consulentes. Essa foi a opção da plataforma Pauliceia 2.0, que deixa disponíveis em seu menu de visualização sete mapas históricos da cidade de São Paulo, cobrindo o período do seu recorte temporal (além da opção do Open Street Map, referente à cidade atual).

Retornando ao geolocalizador descrito acima, o resultado que o algoritmo traz de cada busca de endereço possui três graus de certeza distintos, informado por uma simbologia da imprecisão assim definida: o ícone verde indica endereço localizado no banco de dados, portanto se referindo à localização com alto grau de precisão; o ícone azul indica endereço geocodificado a partir dos pontos do banco de dados; e o vermelho indica endereço extrapolado para além ou aquém do limite dado pelos pontos do banco de dados para aquela rua. Além disso, outra imprecisão é derivada do fato de que o ponto é indicado no eixo da rua, e não junto ao imóvel supostamente localizado. Assim, o que a ferramenta da plataforma Pauliceia 2.0 oferece é o que se chama de "geolocalização relativa", em oposição à absoluta, que retornaria da busca uma localização exata. Nesse sentido, o geolocalizador da plataforma teria o seu uso mais indicado para dois objetivos distintos: permitir o conhecimento da distribuição espacial e temporal de certos eventos ou fenômenos na cidade, para os quais a localização exata não afeta a análise e as conclusões possíveis; e atuar como ferramenta intermediária e auxiliar de pesquisa, destinada a diminuir o escopo espacial das possibilidades de um endereço específico. Como exemplo hipotético da primeira possibilidade, para um estudo das mortes por epidemias na cidade nas primeiras décadas do século XX, não faria diferença significativa a localização exata de cada incidência, mas justamente a sua distribuição espacial na cidade e a variação dela com o tempo. Já um pesquisador que busque identificar o local onde se realizou a emblemática exposição de Anita Malfatti, em 1917, a determinação de uma região aproximada não serve como resultado final da pesquisa, mas pode auxiliar para que se chegue a ele, a partir do cotejamento com outras fontes históricas. ${ }^{6}$

Outra "estratégia de adaptação" fundamental aos historiadores que trabalham com tecnologias, e que se constituiu em verdadeiro princípio metodológico do projeto Pauliceia 2.0, é o não desperdício de qualquer precisão útil que o passado em estudo possa eventualmente oferecer. Que a história é "imprecisa" por definição já está aqui suficientemente reiterado. Mas isso não quer dizer que, no percurso do pesquisador, não se imponham escolhas entre alternativas documentais mais ou menos afeitas a medidas e quantificações. Ou, em outras palavras, mais próximas dos paradigmas científicos da atualidade. No que se refere ao geolocalizador do projeto, a feliz e quase completa simultaneidade temporal entre a já referida instituição do sistema métrico para a determinação da numeração dos imóveis, oficializado em novembro de 1929 (Prefeitura..., 19 nov. 1929), e o levantamento cartográfico SARA Brasil, publicado em 1930, permitiu a construção do geolocalizador com a máxima precisão que a documentação poderia oferecer, conforme a metodologia descrita acima. No 
que se refere especificamente ao SARA Brasil, esse conjunto de cartas representa o melhor "custo/benefício" para qualquer projeto que pretenda fazer uso de geotecnologias para estudar a São Paulo daquele período. ${ }^{7}$ Em outras palavras, se concebêssemos um "índice técnico-histórico" que fosse resultado da multiplicação entre antiguidade e precisão, dificilmente se poderia identificar uma base cartográfica que tivesse um desempenho melhor nesse cálculo do que o SARA Brasil.

Embora a metodologia assim desenvolvida tenha resolvido grande parte dos desafios históricos e computacionais implicados, a sua execução encontrava outro obstáculo importante. A complexidade do banco de dados que dá suporte ao geolocalizador impôs uma limitação ao seu alcance espacial, restrito inicialmente a uma área-piloto, que corresponde de forma aproximada ao centro da cidade, como já informado. Há que reconhecer que essa limitação pode ser causa de frustração para muitos pesquisadores que eventualmente sejam atraídos pelas possibilidades da plataforma mas não encontram a sua área de interesse no escopo do geolocalizador. Para um projeto que se pretende aberto e colaborativo, essa limitação pode ser muito prejudicial. A saída proposta pela equipe do projeto para esse problema é, justamente, aprofundar a aposta na abertura e na colaboração. Pesquisadores ou grupos interessados em incorporar regiões da cidade ao geolocalizador podem eles mesmos contribuir.

\section{Os interessados são bem-vindos}

Das atividades do projeto, algumas não são espacialmente dependentes, como o desenvolvimento do algoritmo do geolocalizador, ou das interfaces da plataforma. Outras atividades são dependentes do espaço, como o georreferenciamento de mapas históricos e a vetorização do sistema viário, mas podem ficar a cargo da equipe do projeto, pois não representam carga de trabalho e investimento de energia e tempo tão significativos, como se dá com a construção do banco de dados da numeração. Assim, se os interessados se encarregam dessa tarefa específica, com a assessoria da equipe do projeto, a área espacial que lhes interessa pode ser incorporada à base do geolocalizador sem grandes dificuldades.

No estágio atual do projeto, já houve tempo para isso começar a acontecer: as regiões do Pari e do Bom Retiro, não pertencentes de início à área-piloto, vêm sendo integradas à base do projeto. A motivação para tal parte do interesse de uma mestranda em história da Universidade Federal de São Paulo, ${ }^{8}$ participante do grupo Hímaco, ${ }^{9}$ que pesquisa o desenvolvimento do mercado imobiliário no Pari, e de um grupo de pesquisas liderado por um dos autores do presente artigo, dedicado a estudar as relações entre a saúde pública e os perfis populacional e cultural do bairro do Bom Retiro. Ainda que ambas as iniciativas tenham relação muito próxima com a equipe do projeto, não fazem parte ostensiva do seu cronograma de trabalho e servem como abordagens experimentais para a ampliação e o aprimoramento da metodologia. O leitor pode acompanhar o andamento das incorporações de novas áreas ao projeto na própria plataforma: para isso, basta "ligar" a camada "streets pilot area", que contém o sistema viário vetorizado até o momento. Se a pretensão da equipe do projeto fizer sentido, desde o tempo da escrita do presente artigo 
até o tempo da sua leitura na revista, o geolocalizador terá abrangido outras regiões da cidade, configurando um mosaico em permanente construção como a melhor imagem da base espacial do projeto. Portanto, aqui como em outras questões centrais do projeto, reitera-se a aposta no trabalho aberto e colaborativo para a superação dos inúmeros e significativos desafios interpostos. ${ }^{10}$

\section{Segunda parada: as tecnologias, o trabalho colaborativo e a livre circulação do conhecimento}

É recorrente a associação das humanidades digitais com um certo ethos colaborativo e de valorização do compartilhamento e da livre circulação do conhecimento (Greenspan, 2016; Spiro, 2012). Como afirma Patrik Svensson (2016, p.490), "as humanidades digitais são frequentemente descritas como inerentemente colaborativas, não apenas a área, mas também suas tecnologias, projetos e pessoas. A colaboração é um parâmetro ativo e visível na narrativa e na estruturação das humanidades digitais. Não trabalhar em colaboração é muitas vezes interpretado como uma exceção". ${ }^{11}$ As próprias tecnologias utilizadas, sem dúvida, fornecem a condição para a realização prática desses princípios teóricos. Não é novidade alguma que o trabalho científico em geral se desenvolve cada vez mais em rede, e as humanidades partilham dessa tendência, claramente suportada e estimulada pelas tecnologias digitais. ${ }^{12}$

$\mathrm{Na}$ verdade, esse fenômeno vai muito além do universo acadêmico e científico, como projetos do tipo da Wikipedia e do Open Street Map claramente demonstram. O que ficou conhecido como crowdsourcing sintetiza o novo cenário aberto e colaborativo que a rede mundial de computadores hoje comporta, como desdobramento da afirmação da denominada web 2.0, desde os primeiros anos desse século (Terras, 2016). A nova internet assim referida é aquela em que seus fluxos passaram a ser bidirecionais, rompendo com a mão única até então predominante, que ia do produtor do conteúdo ao seu leitor/consulente. ${ }^{13}$

Retornando aos ecossistemas acadêmicos e de pesquisa, um dos impactos mais significativos dessas possibilidades exponencialmente ampliadas de publicação e participação é o questionamento das fronteiras tradicionais que historicamente separaram o produtor do consumidor do conhecimento. ${ }^{14}$ Resta à academia evitar a cegueira que nega o fenômeno e pode levar a uma inação isolacionista e procurar explorar as suas possibilidades mais interessantes e profícuas, como de resto tem sido repisado com relação ao tema do uso das tecnologias na produção do conhecimento em humanidades. ${ }^{15}$

Daí a pertinência do movimento da chamada ciência aberta, ou cidadã, que busca ampliar o alcance social da produção do conhecimento a partir da incorporação de contingentes extrauniversitários no fazer científico (Albagli, Maciel, Abdo, 2015). À perda do monopólio da produção do conhecimento pelas universidades e centros de pesquisa, a ciência aberta responde com a proposição de um deslocamento e enriquecimento das atribuições dessas instituições: além de, obviamente, continuar a produzir conhecimento, elas estão em lugar privilegiado para organizar a interlocução entre os diversos atores envolvidos. ${ }^{16}$ Por outro lado, os graus de abertura que a ciência pode experimentar são variados, indo desde um nível mais restrito, correspondendo à utilização do produto final da pesquisa pelo público 
em geral, até a própria concepção do projeto e de seus objetivos com a participação de comunidades envolvidas (Parra, 2015). Como se verá a seguir, o projeto Pauliceia 2.0 se encontra em um ponto intermediário entre esses extremos.

\section{O Pauliceia 2.0 em busca de sua comunidade}

No percurso aqui desenvolvido, a metodologia proposta para ampliar o alcance espacial do geolocalizador da plataforma forneceu o pretexto para se tratar da ética aberta e colaborativa das humanidades digitais. Mas a abertura do projeto não se restringe a ela. Obviamente, o produto final do projeto, uma plataforma para o mapeamento colaborativo da história da cidade de São Paulo, já é em si um distintivo de ciência aberta. Contudo, para que a plataforma reflita as necessidades e os interesses de seus potenciais usuários depende de outras "janelas colaborativas". Os eventos de lançamento do projeto e da versão beta, respectivamente em 4 de abril de 2017 e 30 de outubro de 2018, ambos no auditório do Arquivo Público do Estado de São Paulo, tiveram o objetivo de engajar a comunidade diretamente atinente ao objeto da plataforma, os pesquisadores da história da cidade no recorte proposto e demais eventuais interessados na discussão e nas atividades da pesquisa. No primeiro evento, por exemplo, a equipe do projeto ouviu diversas sugestões, com destaque para a demanda por incluir o upload de fotografias na plataforma, e também recebeu material de pesquisa atinente ao recorte para subsidiar os testes da equipe de computação. ${ }^{17} \mathrm{O}$ segundo evento, em outubro de 2018, teve o objetivo de convocar interessados em testar a plataforma, de forma a acelerar a correção de problemas técnicos e aperfeiçoar suas funcionalidades e características. Esse período de testes segue aberto, tanto quando da escrita do presente texto, quando provavelmente da sua leitura, pelo que o artigo cumpre também o papel de prosseguir aquele chamamento, pois quanto maior o universo de usuários a experimentar a plataforma, mais rápido o seu aprimoramento. Cabe assinalar, aliás, que o período de testes, a rigor, não tem data de término, pois o retorno dos usuários deve ser sempre um canal privilegiado de resolução de problemas e evolução contínua de qualquer ferramenta digital, particularmente daquelas que se pretendem abertas e colaborativas.

\section{Terceira parada: a afirmação do provisório e a decadência do definitivo}

Aqui se expressa outra mudança das condições de trabalho dos pesquisadores em humanidades provocada por impactos tecnológicos: cada vez mais, os resultados das pesquisas tendem a ser provisórios, em processo de constante reavaliação e aprimoramento, a se distanciar do modelo clássico do deadline implacável que condicionou tradicionalmente a divulgação do conhecimento produzido. Desde a difusão de práticas de preprint em revistas acadêmicas (Packer et al., 2018), até a edição intensa e permanente de plataformas que funcionam por crowdsourcing (como Wikipedia e Open Street Maps), passando por modificações constantes de publicações a partir de resenhas e críticas no próprio ambiente do texto original, ${ }^{18}$ generaliza-se uma prática mais aberta e coletiva, que reconfigura a relação dos pesquisadores com o tempo e com as noções de "término", "definitivo", "finalizado" e "corrigido" (Fyfe, 2012). Burdick et al. (2012) fornecem uma perspectiva ainda mais 
polissêmica das novas configurações da era pós-impresso, aliando implicações autorais e espaciais àquelas temporais já mencionadas:

O impresso oferece tipicamente um único ângulo de visão, organização linear, uma saída de pesquisa caracterizada por finitude e estabilidade e uma escala de documentação e argumentação que deve respeitar as proporções físicas do livro. A era da impressão plus-digital, ao contrário, permite alternar entre várias visualizações dos mesmos materiais ... É extensível no duplo sentido de permitir escalas aparentemente ilimitadas e de ser baseado em processo, e não em produtos. Quando um livro é impresso, ele se estabiliza em uma edição que precisa ser reeditada para ser revisada; um artefato digital pode ser alterado ou revisado em um substrato regravável que suporta taxas de atualização rápidas. O mesmo artefato digital pode levar várias vidas em várias plataformas, com vários autores. Ele pode ser remixado por outros antes, durante e depois de sua 'conclusão' (Burdick et al., 2012, p.123). ${ }^{19}$

O excerto faz a transição do tema da desestabilização temporal da apresentação dos resultados de pesquisas em humanidades digitais para a correlata perda de controle do seu conteúdo e de suas autorias. Também aqui o projeto Pauliceia 2.0 traz subsídios para o debate.

\section{A ameaça da "invasão dos bárbaros"}

A abertura da ciência para leigos costuma trazer implícitos medos e ansiedades com relação à qualidade dos resultados pretendidos. Mesmo a participação de pretensos especialistas, sem controle e monitoramento, pode levar à alimentação de dados sem qualidade, ocasionando eventualmente a degradação da confiabilidade da ferramenta ou publicação em questão, sem mencionar a possibilidade sempre presente de vandalismos digitais. A plataforma Pauliceia 2.0, da maneira como foi concebida, e da forma em que se encontra presentemente disponível, é plenamente acessível a qualquer pessoa interessada, seja apenas para consulta, seja para alimentação de dados (criação de camadas). Para esta, é necessária a criação de um cadastro que é, no entanto, bastante simples e que não exige qualquer qualificação ou titulação do usuário.

Diante dessa configuração, dois cenários se apresentam ao destino da plataforma: ou ela resultará em estrondoso fracasso, e a auditoria da qualidade do que for (muito eventualmente) alimentado poderá ser facilmente realizada por poucos ou mesmo apenas por um ou uma especialista na história de São Paulo do período, ou ela terá sido extremamente bemsucedida, e a enorme quantidade de alimentações implicaria uma auditoria praticamente impossível, dado o grande custo de manter uma equipe altamente qualificada para a tarefa de forma quase exclusiva. Ainda que alimentações mais grosseiramente desqualificadas possam e devam ser identificadas por monitoramentos periódicos da equipe do projeto, é evidente que ela não poderia fazê-lo de maneira extensiva e sistemática para toda e qualquer colaboração em caso de participação maciça de usuários. Kenneth Price (2016, p.137) assim enuncia o dilema: "Como podemos negociar melhor os papéis de especialistas acadêmicos e usuários interessados e, em particular, como podemos estabelecer controle de qualidade sem desencorajar o envolvimento do usuário?". ${ }^{20}$ Há que optar entre um controle maior da participação, e, portanto, uma garantia maior da qualidade, ou uma abertura maior à 
colaboração, e por conseguinte um risco de degradação da confiabilidade da plataforma. A equipe do projeto acabou por escolher a segunda alternativa, porque não vê o dilema de forma absoluta, posto que a quantidade maior de colaboradores tem também uma dimensão qualitativa, onde "mais é melhor".

Isso não significa, no entanto, que não foram desenvolvidas estratégias e concepções para minorar o risco apontado. Em primeiro lugar, a responsabilidade pela qualidade e pela confiabilidade dos dados alimentados à plataforma é do próprio usuário que os alimentou, como em qualquer publicação assinada. Em segundo lugar, há uma aposta da equipe do projeto de que o próprio caráter aberto e colaborativo da plataforma funcione como um controle da qualidade do que for alimentado. A arquitetura planejada (e já parcialmente implantada) prevê alguns mecanismos de interlocução entre os usuários da plataforma, como a possibilidade de escrever e receber notificações e de "seguir" uma camada de interesse, recebendo informações sobre as suas atualizações. Além disso, há a ideia de se trabalhar com "curadores temáticos ou espaciais", que seriam responsáveis por estimular seus pares a colaborar com a plataforma, organizar discussões entre eles, propor publicações com o suporte de visualizações de camadas etc. Por exemplo, um especialista em história da saúde pública de São Paulo poderia cumprir esse papel e organizar dessa forma uma subcomunidade de usuários relacionados ao tema. A curadoria poderia seguir critérios temáticos, como no exemplo citado, ou espaciais, referidos à história de determinados bairros ou regiões da cidade. Se esse cenário se realiza, a hipótese consequente é a de que a própria comunidade será capaz de qualificar as informações da plataforma, não apenas as validando, mas promovendo intercâmbios de perspectivas, de sugestões e de atualizações bibliográficas etc.

\section{Quarta parada: os custos não reconhecidos da ciência aberta}

A ameaça da perda de qualidade não é o único custo embutido na abertura em direção à ciência aberta. Os pesquisadores envolvidos em projetos com esse perfil acabam normalmente sobrecarregados de trabalho, pois às atividades de pesquisa familiares ao seu cotidiano profissional, que normalmente compõem o cronograma desses projetos, soma-se a necessidade de organizar e praticar a interlocução com a comunidade-alvo do projeto. Ainda que tal ônus possa ser considerado pequeno em relação ao benefício que produz, justamente a realização da ciência aberta, deve-se reconhecer aqui um paradoxo incômodo: os sistemas avaliativos institucionais da produção do trabalho do docente e do pesquisador não valorizam adequadamente os resultados de muitos dos projetos de humanidades digitais. Ferramentas digitais de leitura distante, sistemas de informações geográficas, repositórios inteligentes e visualizações em realidade virtual são exemplos de produtos de projetos muitas vezes complexos e dispendiosos não necessariamente reconhecidos em avaliações de produtividade. De uma forma geral, os critérios de avaliação ainda estão presos ao paradigma do texto escrito e definitivo publicado em papel, vigente desde o aparecimento das primeiras revistas científicas no século XVII (Fitzpatrick, 2012). ${ }^{21}$

Para usar um exemplo referente ao projeto aqui discutido, a própria plataforma como resultado de pesquisa não encontra muita guarida em tabelas de avaliação de produção, 
com valoração no mais das vezes bastante distante do que se atribui a um artigo em revista especializada, por exemplo. É evidente que essa situação não estimula o desenvolvimento de projetos inovadores de ciência aberta, caso de muitas das iniciativas em humanidades digitais.

Além disso, há outras incompatibilidades entre tais projetos e as formas tradicionais de divulgar os resultados de pesquisas: a dificuldade em se publicar artigos com muitos coautores (Edmond, 2016, p.55). Trabalhos em humanidades digitais costumam ser interdisciplinares (Pimenta, 2019) e não raro articulam saberes técnicos e teóricos em níveis tais que essa mesma distinção se torna questionável (Burdick et al., 2012, p.49-50). Assim como ocorre em muitas pesquisas de ciências naturais e exatas, as humanidades digitais podem fazer uso de máquinas e laboratórios, sem que por isso os seus operadores cumpram qualquer papel secundário ou subordinado na consecução dos resultados finais. Na síntese de Alexander Reid (2012, p.356):

Tipicamente, estudiosos de humanidades trabalham sozinhos enquanto pesquisam bancos de dados, arquivos e prateleiras de bibliotecas; lendo monografias, ensaios e artigos e compondo o seu conhecimento. É incomum a produção de conhecimento em humanidades aparecer com mais de dois autores, sem falar nas longas listas de autores que acompanharão o trabalho nas ciências, por exemplo. Embora a tecnologia industrial tardia não tenha determinado essas práticas, elas se tornaram parte do conjunto da produção acadêmica. E, assim como seria difícil para uma pessoa produzir conhecimento científico sem colaboradores, é um desafio colaborar nas ciências humanas. Dado que a pesquisa opera efetivamente com um único autor, é necessário inventar novas funções para participantes adicionais. Embora haja certamente exemplos de colaborações notáveis e de longa data nas humanidades, elas são a exceção à regra. À medida que as humanidades mudam para uma configuração digital, no entanto, essas práticas estão mudando, e isso já é aparente no campo das humanidades digitais, onde a pesquisa indica uma quantidade crescente de colaboração. ${ }^{22}$

Daí que se conclua que os artigos que apresentem os objetivos e os resultados de pesquisas em humanidades digitais devessem ter todos os envolvidos como autores. A experiência da equipe do projeto Pauliceia 2.0, e, antes disso, do próprio grupo de pesquisas Hímaco, é que fazer valer essa perspectiva, no ambiente das ciências humanas, ainda é bastante difícil. A maioria das revistas acadêmicas vê com maus olhos uma imensa autoria coletiva, como também muitos dos já citados sistemas avaliativos do trabalho docente.

\section{Considerações finais}

O que ora se apresenta é um resultado parcial de um projeto de pesquisa. Seria assim em qualquer momento, independentemente da data da publicação do presente artigo, dado o caráter "permanentemente provisório" do seu "produto final", a plataforma Pauliceia 2.0, como discutido acima. Independentemente disso, a sua divulgação por esse e outros meios possíveis cumpre a finalidade de otimizar as possibilidades de sucesso, pois uma plataforma colaborativa necessita ser conhecida por seus usuários potenciais. Não apenas o engajamento de colaboradores dá sentido à existência da plataforma, como ele cumpre também o papel de viabilizar o seu aprimoramento contínuo, por meio de testes voluntários da atual versão beta e das críticas e sugestões a eles associadas. 
Para além desse objetivo ostensivo, voltado para a divulgação da plataforma, buscouse também oferecer algum material empírico que desse suporte ao debate do uso de tecnologias nos estudos do passado. Evidentemente, a experiência do projeto Pauliceia 2.0 não dá conta das possibilidades da presença das tecnologias digitais no ambiente de trabalho do historiador, tampouco dá subsídio para refletir acerca de toda a complexidade das transformações metodológicas e epistemológicas envolvidas. Mas é pretensão da equipe do projeto que, em alguma medida, ela possa contribuir para o debate. No estágio em que se encontram as humanidades digitais, particularmente no Brasil, o intercâmbio de perspectivas e de aprendizados resultantes de iniciativas pioneiras e isoladas pode ajudar significativamente na superação dos nada negligenciáveis desafios envolvidos. Afinal de contas, é da ética da ciência aberta o compartilhamento não apenas dos resultados, mas dos problemas e das soluções que vieram antes deles.

\section{AGRADECIMENTOS}

O Projeto Pauliceia 2.0 teve financiamento do Programa eScience, da Fapesp (Processo 2016/04846-0), de janeiro de 2017 a janeiro de 2019.

Os autores gostariam de fazer um agradecimento especial aos demais membros da equipe do projeto, aqui nomeados: Ana Maria Alves Barbour, Carlos Alberto Noronha, Cintia Rodrigues de Almeida, Denis Taveira de Lima, Eduardo Goiabeira, Ester Dantas Reis Nunes, Gabriel Sansigolo, Gilberto Ribeiro de Queiroz, Ivan Dardi, Janaina Yamamoto Santos, Luanna Mendes do Nascimento, Marta Cristina Pacoret Rodríguez, Michael Page, Monaliza Caetano dos Santos, Orlando Guarnier Farias, Priscila Machado Meireles, Rodrigo Monteiro Mariano, Vitória Martins Fontes da Silva, Wania Mazzarello e Yasmin Wassef. A atuação de todos e de cada um possibilitou os resultados alcançados pelo projeto, entre os quais o presente artigo.

\section{NOTAS}

${ }^{1}$ O projeto é uma parceria entre a Universidade Federal de São Paulo (campi de Guarulhos e de São José dos Campos), o Instituto Espacial de Pesquisas Espaciais, o Arquivo Público de São Paulo e a Emory University.

${ }^{2}$ Por exemplo, uma das camadas já alimentadas à plataforma é a mancha da enchente de 1929 em São Paulo. Sobre como o mapa respectivo foi construído, ver Santos et al. (2014).

${ }^{3}$ Sobre esse e outros aspectos mais diretamente computacionais do projeto, evidentemente muito mais abrangentes e complexos do que o desenvolvimento do algoritmo do geolocalizador aqui discutido, consultar Ferreira et al. (2018).

${ }^{4}$ [Nota do editor] Imagem colorida disponível em: <www.scielo.br/hcsm>.

${ }^{5}$ Um pesquisador que vem desenvolvendo reflexões e metodologias importantes sobre o tratamento da imprecisão no desenvolvimento de SIGs históricos é o professor Carlos Valencia, da Universidade Federal Fluminense (UFF). Ver, por exemplo, Valencia, Gil (2016). Nessa obra, inclusive, faz-se uso dos "borrões" como discutido (p.108, 178, 214, 250).

${ }^{6}$ Sem utilização do geolocalizador do Pauliceia 2.0, até porque ele não se encontrava disponível à época, mas fazendo uso da mesma metodologia aqui descrita, o artista plástico Edgard Santo Moretti chegou ao endereço exato da famosa exposição de Anita Malfatti, em 1917 (Rocha, 27 jan. 2019).

${ }^{7}$ Trata-se de um conjunto de oitenta cartas, em escalas 1:1000 e 1:5000, resultantes de um dos primeiros levantamentos aerofotogramétricos de uma grande cidade no mundo. Sobre a qualidade científica do SARA Brasil, mesmo para parâmetros atuais, ver Lima (2013).

${ }^{8}$ Ana Maria Barbour conta com a colaboração de Wania Mazzarello para a sua pesquisa.

${ }^{9}$ O grupo Hìmaco (Histórias, Mapas e Computadores) faz parte da equipe do projeto e está cadastrado no Conselho Nacional de Desenvolvimento Científico e Tecnológico (CNPq) desde 2011 (ver <dgp.cnpq.br/ dgp/espelhogrupo/3777602011014869>). 
${ }^{10}$ É importante salientar que toda a tecnologia utilizada no projeto é livre e aberta, e o que foi e está sendo desenvolvido se encontra disponível para os interessados em elaborar projetos similares dedicados a outros recortes temporais e espaciais.

${ }^{11}$ Tradução livre do original: "The Digital Humanities is often described as inherently collaborative, not just the field, but also its technologies, projects, and people. Collaboration is an active and visible parameter in the narrative and framing of digital humanities. Not working collaboratively is often construed as an exeception".

${ }^{12}$ No Brasil, um núcleo importante que desenvolve reflexões sobre o tema é o Programa de Pós-graduação em Ciência da Informação da Universidade Federal do Rio de Janeiro (UFRJ) e do Instituto Brasileiro de Informação em Ciência e Tecnologia (Ibict), ao qual se vincula o Laboratório em Rede de Humanidades Digitais (LarHuD). Uma produção originária desse programa e bastante pertinente à perspectiva do presente artigo é Aguiar (2012).

${ }^{13}$ Ainda que não caiba no escopo deste artigo ir muito além, sempre é importante ressalvar que tal fenômeno tecnológico tem outras muitas e polissêmicas consequências, bem mais obscuras, tais como os avanços da mercantilização do conhecimento ou os estados de hipervigilância que denúncias como as de Edward Snowden trouxeram à luz (Burdick et al., 2012, p.80-81).

${ }^{14} \mathrm{O}$ que motivou o neologismo prosumer (Burdick et al., 2012, p.135). No entanto, aqui também existem efeitos nem sempre desejáveis, como a degradação da autoridade científica produzida por movimentos irracionalistas do tipo do terraplanismo e contra a vacinação, por exemplo.

${ }^{15}$ No campo da história, também no Brasil, já há experiências exitosas nessa direção, com destaque para o Atlas da América Lusa, projeto colaborativo coordenado pelo professor Tiago Gil, da Universidade de Brasília (UnB) (disponível em: <http://lhs.unb.br/atlas/In\%C3\%Adcio >). Para um relato do projeto, ver Gil (2019). No âmbito da história urbana, o Pauliceia 2.0 tem muitas identidades com os projetos ImagineRio (disponível em: <https://imaginerio.org/\#en>) e Mapa Histórico Digital de Belo Horizonte (disponível em: $<$ https://mapahistoricobh.wixsite.com/historicobh>).

${ }^{16}$ Daí a proposta das curadorias temáticas do projeto, explicada mais adiante.

${ }^{17}$ Particularmente especial foi a contribuição das professoras Ana Lucia Duarte Lanna e Sarah Feldman, ambas da Faculdade de Arquitetura da Universidade de São Paulo (FAU/USP), que disponibilizaram dados extensivos de suas pesquisas sobre a cidade à equipe do projeto. O estudo de Feldman acerca das indústrias do Bom Retiro na primeira metade do século XX subsidiaram a criação de uma camada na plataforma.

${ }^{18}$ Um dos casos mais interessantes é a série "Debates in the digital humanities". Ver, por exemplo, a edição de 2019 (Gold, Klein, 2019).

${ }^{19}$ Tradução livre do original: "Print typically offers a single viewing angle, linear organization, a research output characterized by finitude and stability, and a scale of documentation and argumentation that has to respect the physical proportions of the book. The digital print-plus era, in contrast, allows for toggling back and forth between multiple views of the same materials ... It is extensible in the double sense of allowing for seemingly unlimited scale and of being process - rather than product - based. When a book goes to print, it stabilizes in a edition that has to be reissued in order to be revised; a digital artifact can be altered or revised on a rewritable substrate that supports rapid refresh rates. The same digital artifact can lead multiples lives on multiple platforms, with multiple authors. It can undergo remixing by others before, during, and after its 'completion'".

${ }^{20}$ Tradução livre do original: "How can we best negotiate the roles of scholarly specialists and interest users, and, in particular, how can we establish quality control without discouraging user involvement?".

${ }^{21}$ Buscando subsidiar novos parâmetros que façam maior justiça a trabalhos em história digital, a American Historical Association produziu recentemente um "Guidelines for the Professional Evaluation of Digital Scholarship by Historians" (2015).

${ }^{22}$ Tradução livre do original: "Tipically, humanities scholars work alone while searching databases, archives, and library shelves; reading monographs, essays, and articles; and composing their scholarship. It is unusual for humanities scholarship to appear with more than two authors, let alone the long lists of authors that will accompany work in the sciences, for example. While late industrial technology did not determine these practices, they became part of the assemblage of scholarly production. And just as it would be difficult for a single person to produce scientific scholarship without collaborators, it is challenging to collaborate in the humanities. Given that the assemblage operates effectively with a single author, one essentially has to invent new roles for additional participants. While there are certainly examples of notable, long-standing collaborations in the humanities, they are the exception to the rule. As the humanities shift into a digital assemblage, however, these practices are changing, and this is already apparent in digital humanities field, where research indicates a growing amount of collaboration". 


\section{REFERÊNCIAS}

AGUIAR, Leandro Coelho de.

Cultura digital e fazer histórico: estudos dos usos e apropriações das tecnologias digitais de informação e comunicação no ofício do historiador. Dissertação (Mestrado em Ciência da Informação) - Universidade Federal do Rio de Janeiro, Rio de Janeiro. 2012.

ALBAGLI, Sarita; MACIEL, Maria Lucia; ABDO, Alexandre (Org.).

Ciência aberta: questões abertas. Brasília: Ibict; Rio de Janeiro: Unirio. Disponível em: <http:// livroaberto.ibict.br/bitstream/1/1060/1/ Ciencia\%20aberta_questoes\%20abertas_ PORTUGUES_DIGITAL\%20(5).pdf>. Acesso em: 2 nov. 2019. 2015.

BODENHAMER, David.

History and GIS: implications for the discipline. In: Knowles, Anne (Ed.). Placing history: how maps, spatial data, and GIS are changing historical scholarship. Redlands: Esri Press. p.219-233. 2008.

BRUNO, Ernani Silva.

História e tradições da cidade de São Paulo: burgo de estudantes (1828-1872). Rio de Janeiro: José Olímpio. 1954.

BURDICK, Anne et al.

A short guide to the digital humanities. Cambridge, London: MIT Press. 2012.

CHURCHILL, Robert; HILLIER, Amy.

Teaching with GIS. In: Knowles, Anne (Ed.). Placing history: how maps, spatial data, and GIS are changing historical scholarship. Redlands: Esri Press. p.61-94. 2008.

EDMOND, Jennifer.

Collaboration and infrastructure. In:

Schreibman, Susan; Siemens, Ray; Unsworth, John (Ed.). A new companion to digital humanities. Malden: Blackwell. p.54-65. 2016.

FERREIRA, Karine et al.

A platform for collaborative historical research based on volunteered geographical information. Journal of Information and Data Management, v.9. p.291-304. Disponível em: <https://periodicos. ufmg.br/index.php/jidm/article/view/426>. Acesso em: 2 nov. 2019. 2018.

FITZPATRICK, Kathleen.

Beyond metrics: community authorization and open peer review. In: Gold, Matthew K. (Ed.). Debates in the digital humanities. Minneapolis: University of Minnesota Press. p.452-459. 2012.

FYFE, Paul.

Eletronic errata: digital publishing, open review, and the future of correction. In: Gold, Matthew
K. (Ed.). Debates in the digital humanities. Minneapolis: University of Minnesota Press. p.259-291. 2012.

GIL, Tiago.

Experiências colaborativas no projeto Atlas Digital da América Lusa. Educação em Foco, v. 24, n.2, p.593-614. 2019.

GOLD, Matthew; KLEIN, Lauren (Ed.). Debates in the digital humanities. Minneapolis: University of Minnesota Press. Disponível em: <https://dhdebates.gc.cuny.edu/read/untitledf2acf72c-a469-49d8-be35-67f9ac1e3a60/section/ bb4fc28f-96e5-43bb-8933-b9a17d0dd0c9\#cvi>. Acesso em: 2 nov. 2019. 2019.

GREENSPAN, Brian.

Are digital humanists utopian? In: Gold, Matthew; Klein, Laura (Ed.). Debates in the digital humanities. Minneapolis: University of Minnesota Press. p.393-409. 2016.

GREGORY, Ian; ELL, Paul.

Historical GIS: technologies, methodologies and scholarship. Cambridge: Cambridge University Press. 2007.

\section{GUIDELINES...}

Guidelines for the Professional Evaluation of Digital Scholarship by Historians. American Historical Association. Disponível em: <https:// www.historians.org/teaching-and-learning/ digital-history-resources/evaluation-of-digitalscholarship-in-history/guidelines-for-theprofessional-evaluation-of-digital-scholarshipby-historians>. Acesso em: 2 nov. 2019. 2015.

IBGE.

Instituto Brasileiro de Geografia e Estatística. Tabela 1287 - População dos municípios das capitais e Percentual da população dos municípios das capitais em relação aos das unidades da federação nos Censos Demográficos. Disponível em: <https://sidra. ibge.gov.br/tabela/1287\#/n6/3550308/v/591/p/ all/l/v,p,t/resultado >. Acesso em: 31 out. 2019. 2011.

KNOWLES, Anne.

GIS and history. In: Knowles, Anne (Ed.). Placing history: how maps, spatial data, and GIS are changing historical scholarship. Redlands: Esri Press. p.1-25. 2008.

LIMA, Erly Caldas.

O levantamento pioneiro da SARA Brasil: histórico, tecnologia empregada e avaliação dos produtos. Dissertação (Mestrado em Engenharia) - Escola Politécnica, Universidade de São Paulo, São Paulo. 2013. 
PACKER, Abel et al.

Aos 20 anos, a Rede SciELO atualiza prioridades e avança para a ciência aberta. SciELO em Perspectiva. Disponível em: <https://blog.scielo. org/blog/2018/09/17/aos-20-anos-a-rede-scieloatualiza-prioridades-e-avanca-para-a-cienciaaberta>. Acesso em: 2 nov. 2019. 2018.

PARRA, Henrique.

Ciência cidadã: modos de participação e ativismo informacional. In: Albagli, Sarita; Maciel, Maria Lucia; Abdo, Alexandre (Org.). Ciência aberta: questões abertas. Brasília: Ibict; Rio de Janeiro: Unirio. p.121-141. Disponível em: <http://livroaberto.ibict.br/bitstream/1/1060/1/ Ciencia\%20aberta_questoes\%20abertas_ PORTUGUES_DIGITAL\%20(5).pdf>. Acesso em: 2 nov. 2019. 2015.

PIMENTA, Ricardo M.

Das iniciativas em humanidades digitais e suas materialidades: relato de um laboratório em construção contínua. Memória e Informação, v.3, p.1-14. 2019.

PREFEITURA...

Prefeitura Municipal de São Paulo. Código de Obras Arthur Saboya, de 1929. Lei n.3.427. Revisado e Consolidado pelo Ato n.663, de 10 de agosto de 1934. Disponível em: <https:// leismunicipais.com.br/SP/SAO.PAULO/LEI-34271929-SAO-PAULO-SP.pdf $>$. Acesso em: 2 nov. 2019. 19 nov. 1929.

PRICE, Kenneth M.

Social scholarly editing. In: Schreibman, Susan; Siemens, Ray; Unsworth, John (Ed.). A new companion to digital humanities. Malden: Blackwell. p.137-149. 2016.

REID, Alexander.

Graduate education and the ethics of the digital humanities. In: Gold, Matthew K. (Ed.). Debates in the digital humanities. Minneapolis: University of Minnesota Press. p.350-367. 2012.

ROCHA, Pedro.

Artista descobre atual endereço do local que recebeu exposição histórica de Anita Malfatti. $O$ Estado de São Paulo, Caderno Cultura. Disponível em: <https://cultura.estadao.com.br/noticias/ artes, artista-descobre-atual-endereco-do-localque-recebeu-exposicao-historica-de-anitamalfatti,70002694355>. Acessso em: 2 nov. 2019. 27 jan. 2019.

SANTOS, Fábio Alexandre dos et al. A enchente de 1929 na cidade de São Paulo: memória, história e novas abordagens de pesquisa. Revista do Arquivo Geral da Cidade do Rio de Janeiro, v.8. p.149-166. Disponível em: $<$ http://wpro.rio.rj.gov.br/revistaagcrj/wpcontent/uploads/2016/11/e08_a8.pdf $>$. Acesso em: 2 nov. 2019. 2014.

\section{SÃO PAULO.}

Comissão do IV Centenário da Cidade. São Paulo Antigo: plantas da cidade. São Paulo: Melhoramentos. 1954.

SPIRO, Lisa.

"This is why we fight": defining the values of the digital humanities. In: Gold, Matthew K. (Ed.). Debates in the digital humanities. Minneapolis: University of Minnesota Press. p.16-35. 2012.

SVENSSON, Patrik.

Sorting out the digital humanities. In:

Schreibman, Susan; Siemens, Ray; Unsworth, John (Ed.). A new companion to digital humanities. Malden: Blackwell. p.476-492. 2016.

TERRAS, Melissa.

Crowdsourcing in the digital humanities. In: Schreibman, Susan; Siemens, Ray; Unsworth, John. (Eds.). A new companion to digital humanities. Malden: Blackwell. p.420-438. 2016.

VALENCIA, Carlos; GIL, Tiago.

O retorno dos mapas: sistemas de informação geográfica em história. Porto Alegre: Ladeira Livros. 2016.

WHITE, Richard. Foreword. In: Knowles, Anne (Ed.). Placing history: how maps, spatial data, and GIS are changing historical scholarship. Redlands: Esri Press. p.IX-XI. 2008.

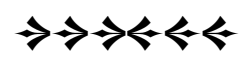

